\title{
Hybrid Power Generation System Using Solar and Biomass Power Generation System
}

\author{
Anjali Gupta, Sanjay Maurya, Ajay Kumar
}

\begin{abstract}
The renewable energy is the future of human race without optimally harnessing renewable energy human race will not move forward. As the non-renewable source of energy are moving towards depletion each day, the technological advancement toward renewable energy is moving with a fast pace. Each day we heard about a new technology, in this paper a hybrid system energy system is discussed. The hybrid system is achieved by utilizing solar energy and biomass energy. The system using a set of solar panel, biomass gasifier, boiler, steam turbine, generator, inverter and battery.
\end{abstract}

Keywords: Biomass energy, solar energy, gasifier, turbine, generator, inverter, battery, solar panel module.

\section{INTRODUCTION}

The solar power and biomass are two most prominent harnessing[1][2]. So, in this project a hybrid system for power generation is specially designed for harnessing both power when excess power need or when one source is not available for power generation[3]. By designing this system we are removing the most disturbing curve of solar power generation the duck curve[4]. In this project two power generation system works in parallel for generating electrical power and supporting one another when one system is down or unable to generate power for example solar power can't be generated in night but we can use biomass power at night. The two system are coupled with each other and excess power generated is stored in batteries which are specially designed for storing excess power. This system works in all-weather condition and at any time. The designed prototype have many different use at many different locations like it can power houses, commercial buildings, factories, community buildings and many more.

\section{TECHNOLOGIES USED}

Biomass gasifier: The biomass gasifier is a device which is used for converting the biomass into gaseous form by using compost making technique and the by-product of converted product is compost which will be used for improving the fertility of soil[5]. renewable power source which is available for

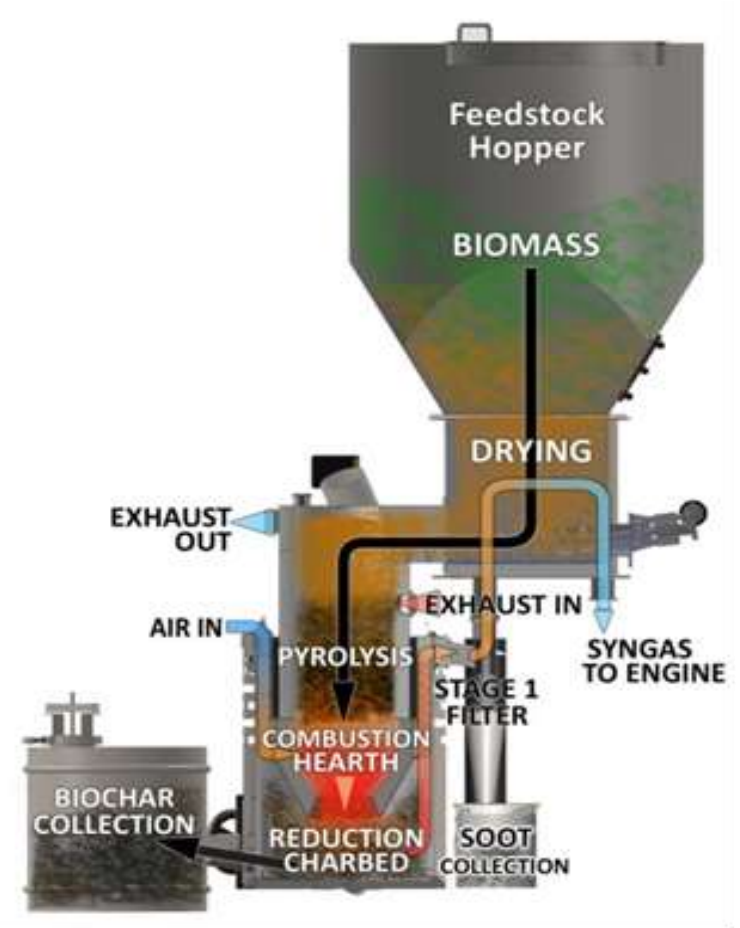

Figure 1: Biomass Gasifier reference image.

Boiler: The boiler is an important unit of any biomass power plant in this system boiler is used to boil water and convert it into steam by the help of gas produced in biomass gasifier which act as fuel for boiling the water. The boiler create a required pressure before releasing steam further[6].

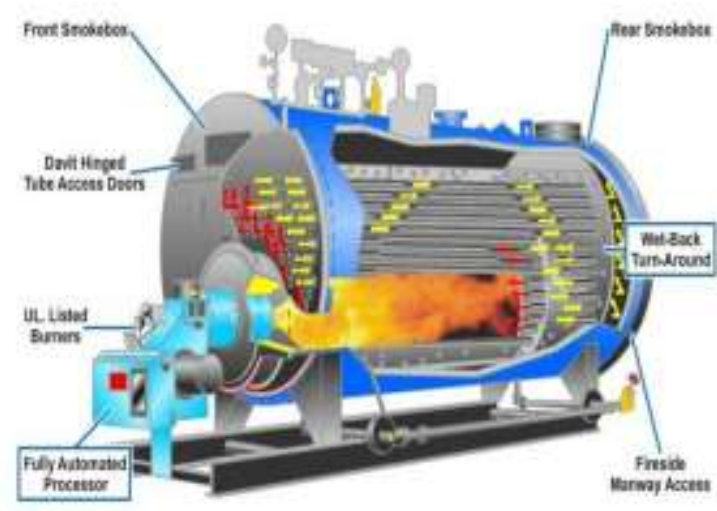

Figure 2: Boiler reference image

Anjali Gupta, Department of Electrical \& Electronics Engineering, Noida Institute of Engineering and Technology, Noida, U.P. India. (Email: researchnietip@gmail.com)

Sanjay Maurya, Department of Electronics \& Communication Engineering, Noida Institute of Engineering and Technology, Noida, U.P. India. (Email: researchnietip@gmail.com)

Ajay Kumar, Department of Mechanical Engineering, Noida Institute of Engineering and Technology, Noida, U.P. India. (Email: researchnietip@gmail.com) 
Steam Turbine: The steam turbine is used for converting kinetic energy of steam into mechanical energy. When the steam hits the propellers of turbine with a predefined pressure, the propellers start rotating, thus creating a rotational energy which is fed to system further[7].

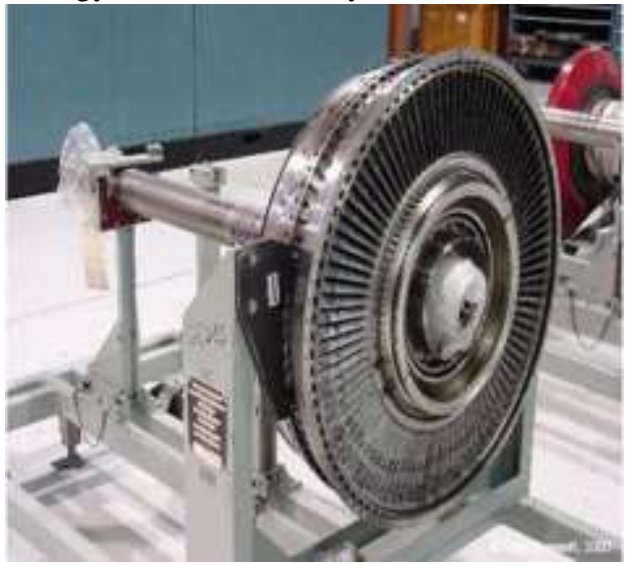

Figure 3: Steam Turbine reference image

Generator: The generator converts mechanical energy into electrical energy. The generator have a rotor and stator, the stator have many copper wire coil connected with each other in series as required for generating required voltage of electrical energy and in stator many neodymium magnets. When the rotor rotates inside the stator coil it generates a variable magnetic field which excites the coil and generates an electrical current which lead to generation of electrical energy[8].

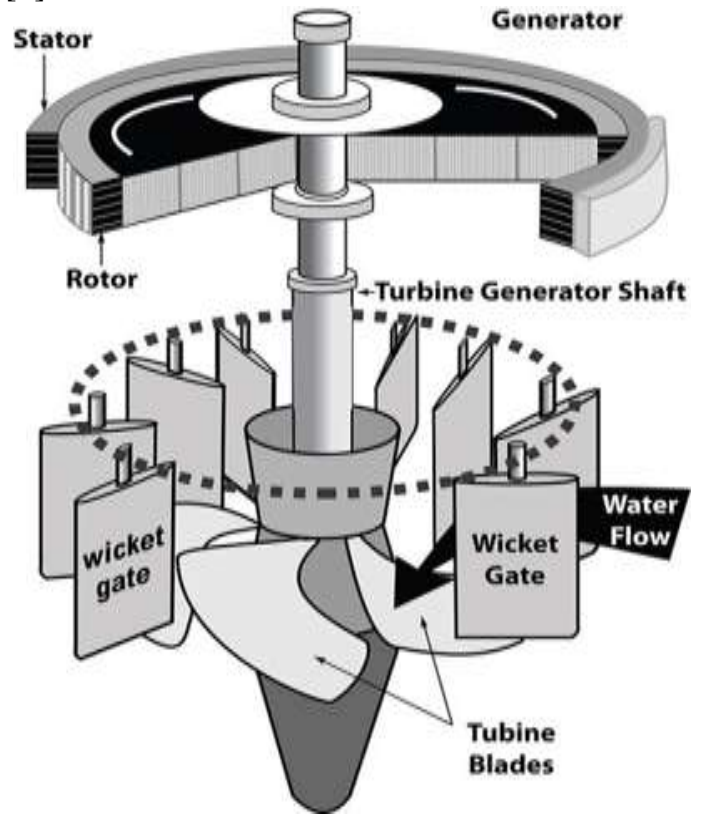

Figure 4: Generator Connection with turbine schematics

Solar panel module: The solar panel modules are used for converting solar energy into electrical energy by using photoelectric effect. When sun light or any light falls on solar cell due to the properties of semiconductor material used with doping material, the semiconductor material molecules starts exciting and releasing electrons which are responsible of electrical power generation in system[9].

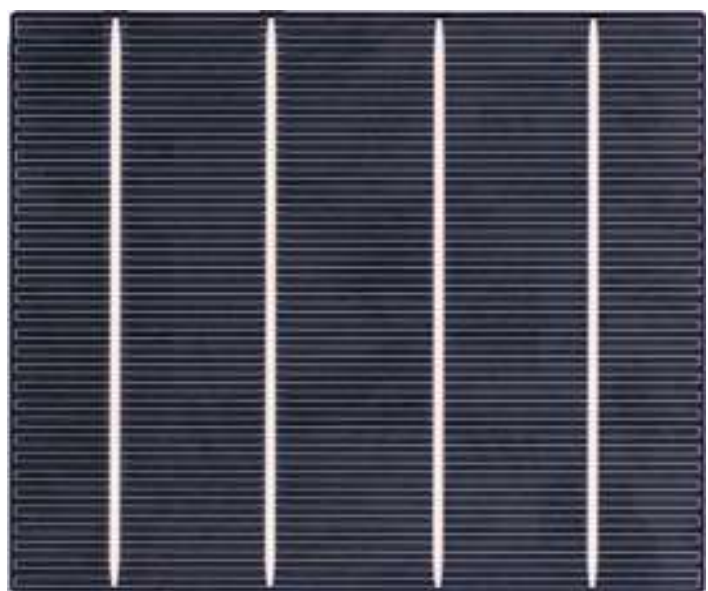

Figure 5: Solar cell

Battery: The battery is an electrochemical device used for storing electrical energy into it by converting electrical energy into chemical energy. The batteries comes in different types, size and shapes and play a prominent role in our future[10][11]

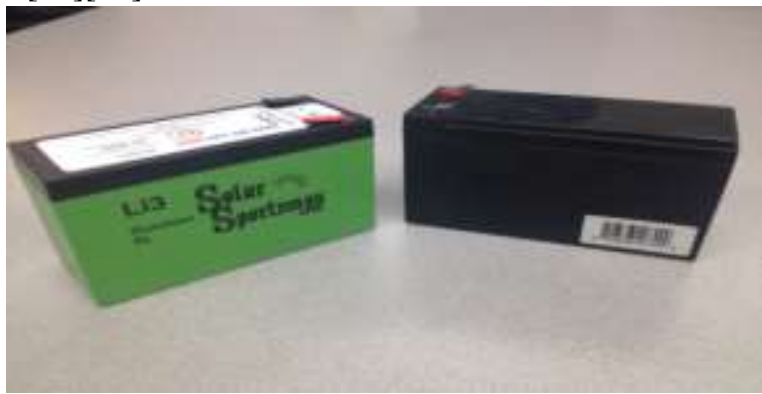

Figure 6: Lead acid batteries

Inverter: The inverter is device which converts DC power into AC by using switching technique. The converted AC power then can be fed to any appliances[12].

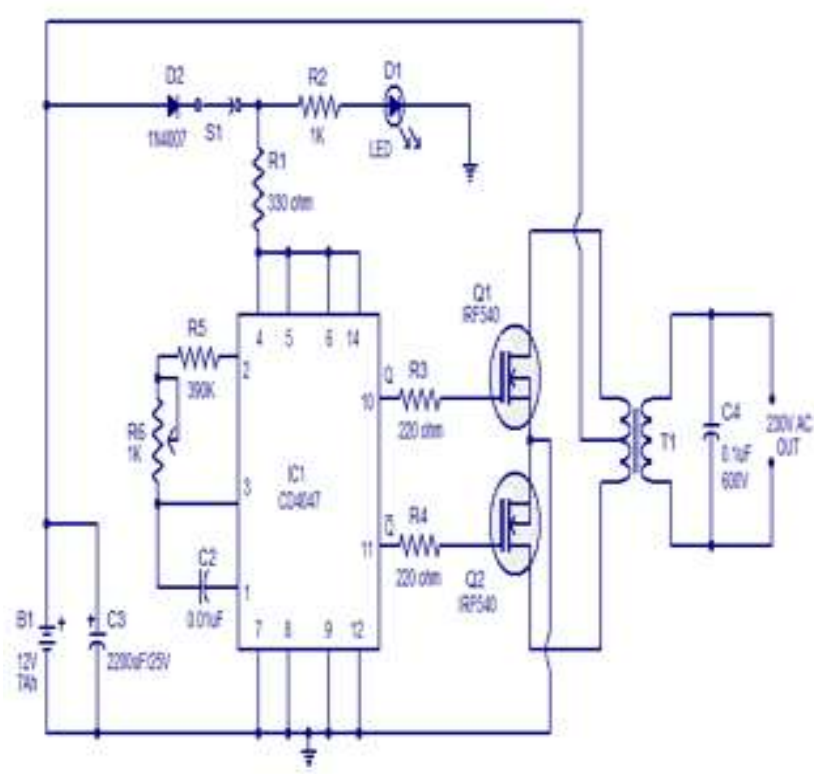

Figure 7: Inverter Circuit diagram 


\section{PROPOSED METHOD \& RESULTS}

The biggest issue of solar energy is that it is not available 24 hour of the day. And the major issue is ducks curve, the duck curve shows an average trend of power requirement on a day, the most power is required in morning and evening but the solar power production is maximum at day when power requirement is low and when required the most the power generation is at low or nothing. So, for rectifying this issue we designed a hybrid power generation system using solar power generation and biomass power generation system and store excess power generated into lead acid batteries for supplying power instantaneously to user.

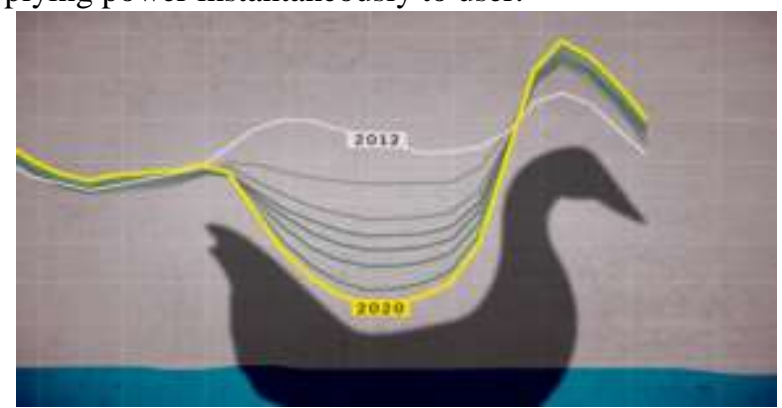

Figure 8: Ducks Curve

The hybrid system works on basic principal of energy conversion, in this system we converted energy form one form to another, the solar panel converts photon energy into electrical energy and biomass power system converts waste into gas and the converted gas is majorly methane and used as flame for boiling water. The steam is used to power generator and electricity is generated. The generated energy is store further. The biomass power system is used when solar power efficiency is down or instantaneously electrical energy required.

\section{WORKING OF PROPOSED SYSTEM}

When sunlight or any light fall on solar panel it start generating electrical energy which is harnessed at peak value by using "Maximum Power Point Tracking (MPPT)". The harnessed power is directly supplied to electrical load when required by converting DC power by using inverter or when not required stored in "lead acid batteries" and when power requirement increases the biomass power generation unit is activated. The gasifier which is used for purifying and storing generated gas from the waste material, the generated gas than fed to boiler unit where the generated methane gas act as fuel for boiling water in boiler and for producing steam. The steam is than pressurised to a level and transferred to steam turbine, the pressurised steam rotates the steam turbine and the steam turbine is connected with generator via a shaft. When the generator rotates it creates electricity which can be stored for fed to load directly. The biomass power generation system is employed for continuous power supply to the load and batteries for compensating instantaneous energy demand.

\section{CONCLUSION}

The system is worked as planed and designed. The hybrid power system using solar and biomass power system solving the issues of clean and continuous energy. This system removed the duck curves issue because coupling with the biomass power system and by employing batteries the excess power is stored for future use. In future the system will be improved by employing new techniques for handling loads smartly and in safe manner.

\section{REFERENCES}

1. P. McKendry, "Energy production from biomass (Part 1): Overview of biomass.," Bioresour. Technol., 2002.

2. A. Miller, "Solar power," Eng., 1998.

3. M. Abdelaziz Mohamed and A. M. Eltamaly, "Modeling of hybrid renewable energy system," in Studies in Systems, Decision and Control, 2018.

4. CAISO, "What the duck curve tells us about managing a green grid," 2013.

5. P. McKendry, "Energy production from biomass (Part 3): Gasification technologies.," Bioresour. Technol., 2002.

6. K. J. Åstroöm and R. D. Bell, "Drum-boiler dynamics," Automatica, 2000.

7. "Steam turbines," Fluid Mech. its Appl., 2015.

8. G. Nicoll and M. J. Boss, "Generators," in Electrical Safety: Systems, Sustainability, and Stewardship, 2014.

9. K. W. Böer, "The physics of solar cells," J. Appl. Phys., 1979.

10. W. D. Hill, "Battery,” English J., 2006.

11. H. Bode and J. Davis, "Lead-Acid Batteries," J. Electrochem. Soc., 2012.

12. J. A. Melkebeek, "Inverter," in Power Systems, 2018. 